\title{
Monitoramento de ações governamentais de combate ao desmatamento por intermédio de ferramentas gerenciais e satelitais ${ }^{3}$
}

\section{Introdução}

Estimativas recentes sobre a perda de cobertura vegetal nativa apontam a América do Sul e a África como os continentes que vêm perdendo mais rapidamente suas florestas ${ }^{4}$. O Brasil, seguido da Indonésia, foram os países com maior área desmatada entre 1990 e 2005. Além de liderar o ranking mundial de desmatamento, o Brasil apresenta também a mais extensa rede de áreas tropicais protegidas 5 . Dentro deste contexto e considerando os possíveis impactos das mudanças climáticas advindos da perda de cobertura florestal nativa ${ }^{6}$, uma série de ações para a prevenção e combate ao desmatamento vêm sendo propostas pelo Governo Federal.

\section{O Departamento de Políticas para} o Combate ao Desmatamento é o órgão governamental responsável pela elaboração de estratégias para a redução do desmatamento.
Entre elas, os Planos de Ação para Prevenção e Controle do Desmatamento nos biomas (PPCDAm e PP(errado) são considerados instrumentos da Política Nacional sobre Mudança do Clima, sendo essenciais para a redução das emissões brasileiras devido ao desmatamento e às mudanças no uso do solo. Portanto, tais planos de ação desempenham importante papel para que o Brasil alcance suas metas de redução das emissões.

O PPCDAm é considerado como a principal política para a redução do desmatamento no País. Ele foi instituído pelo Decreto sem número de 3 de julho de 2003, motivado pelas altas taxa de desmatamento na Amazônia observadas em 2003 e 2004. O PPCDAm é tido como um dos principais responsáveis pelas constantes quedas na taxa anual de desmatamento na Amazônia. 
O objetivo deste artigo é demonstrar as ferramentas utilizadas pelo Ministério do Meio Ambiente para o monitoramento das atividades de combate ao desmatamento. Neste sentido, a seção seguinte intitulada "Monitoramento gerencial do PPCDAm" utiliza o PPCDAm como estudo de caso para relatar como o monitoramento gerencial foi realizado. Em seguida, a seção intitulada "Monitoramento das ações de combate ao desmatamento por dados de satélite" demonstra a utilização de dados satelitais para o monitoramento de ações de combate ao desmatamento na Amazônia e em outras regiões do Brasil.

\section{Monitoramento gerencial do PPCDAm}

Segundo o Decreto sem número de 3 de julho de 2003, o Grupo de Trabalho Interministerial (GPTI) é composto por 17 órgãos. A Comissão Executiva do PPCDAm é composta oficialmente por dez órgãos, e é a principal instância para monitoramento e tomada de decisões para correção de rumos. Constitui uma rede onde as decisões são tomadas por consenso, e órgãos convidados participam com o mesmo peso dos membros permanentes.
O próprio PPCDAm constitui uma rede mais complexa e intricada, onde diversos setores de diferentes órgãos são responsáveis pela execução de cerca de duas centenas de atividades, sistematizadas em um Plano Operativo que explicita prazos e metas gerenciais. A terceira fase do PPCDAm (2012 a 2015) contou com a participação de 36 órgãos federais, e conta com instâncias consultivas junto a governos estaduais, setor privado e sociedade civil organizada.

O monitoramento da execução das atividades previstas no Plano Operativo do PPCDAm é um desafio que se impôs desde o início de sua implementação. A primeira fase do plano, que vigorou de 2004 a 2007, contou com um sistema de monitoramento gerencial on-line em que representantes de cada órgão tinham senhas de acesso que lhes permitiam atualizar informações quanto à execução das atividades sob sua responsabilidade. Sempre que um dado setor não cumpria o prazo previsto para inserir informações no sistema, a equipe no Ministério do Meio Ambiente entrava em contato com o responsável para cobrar o preenchimento do sistema.

3 Este artigo é baseado em apresentação realizada no seminário "Gestão da Informação e Monitoramento de Políticas Sociais", que ocorreu nos dias 11 e 12 de dezembro de 2012, na Escola Nacional de Administração Pública (ENAP), Brasília/DF.

4 FAO \& JRC. Global forest land-use change 1990-2005. FAO Forestry Paper No. 169. Rome; FAO. 2012.

5 TRANCOSO, R et al. Deforestation and Conservation in major waterheds of the Brazilian Amazon. Environmental Conservation, v.36, n.4, 2010.

6 IPCC AR4 WG1. SOLOMON, S. et al. Climate Change 2007: The Physical Science Basis. Cambridge University Press. 2007. 
Cerca de um ano após sua implementação, percebeu-se que, apesar das cobranças, a maioria dos setores não atualizava as informações sob sua responsabilidade. O sistema foi perdendo adesão, até ser totalmente abandonado.

Dentre as causas apontadas para o insucesso dessa experiência, pode-se destacar:

- Alta complexidade do sistema, que exigia que fosse dispensado tempo e esforço dos executores para compreender o que exatamente estava sendo pedido em cada campo;

- Baixa disponibilidade dos executores, envolvidos em diversas outras ações, incluindo o preenchimento de outros sistemas para outras instâncias do governo;

- Ausência de incentivos para promover maior adesão dos executores; e

- Erros do software, que muitas vezes faziam com que textos longos fossem perdidos ao tentar salvá-los.

Em geral, os executores viam o preenchimento do sistema como um esforço complexo e com pouco ou nenhum resultado prático, e não disponibilizavam o escasso tempo de suas equipes para preenchê-lo.

Desse modo, um dos grandes desafios para a segunda fase do PPCDAm (2009 a 2011) foi o desenvolvimento de um sistema de monitoramento capaz de gerar informações sistematizadas sobre o andamento das atividades do Plano Operativo, destacando os principais avanços e dificuldades encontradas pelos executores, de modo a subsidiar a Comissão Executiva na tomada de decisões necessárias para corrigir os rumos da atuação governamental.

No intuito de racionalizar o esforço de coleta, sistematização e apresentação das informações, optou-se por focar apenas os prazos e metas gerenciais do Plano Operativo. Ademais, foram selecionadas para acompanhamento direto pela Comissão Executiva apenas 107, de um total de 211 atividades. Tal seleção teve como critério a relevância imediata sobre o problema central abordado pelo Plano, o "desmatamento ilegal na Amazônia Legal". As demais atividades continuaram em execução e sob monitoramento pelos setores responsáveis.

As 107 atividades selecionadas foram reprocessadas sem perda de conteúdo, o que resultou em um total de 64 atividades, sempre focando as metas estabelecidas no Plano Operativo.

Para atualização das informações foram utilizadas duas estratégias diferentes. Em 2009 e 2011, os responsáveis foram consultados apenas sobre o quanto da meta prevista foi executado, abrindo-se um campo de livre preenchimento, para que fossem inseridas justificativas para o não cumprimento ou quaisquer outras informações que os executores julgassem relevantes. Nesse caso, buscou-se simplificar ao máximo o preenchimento para obter a adesão dos executores. Tal estratégia deu resultado, mas o nível de detalhamento 
das respostas foi em geral muito superficial para balizar a tomada de decisão para correção de rumos.

Em 2010 foi elaborado um sistema de etapas, que visava apreender avanços intermediários para a execução da meta de forma ágil, obtendo assim informações mais completas para a tomada de decisões. Foram realizadas reuniões com os responsáveis por cada uma das 64 atividades monitoradas. Nesses encontros, foi solicitada a participação dos técnicos que atuavam diretamente na execução. Os responsáveis tinham a oportunidade de revisar a meta para o ano, e em seguida cada atividade foi subdividida em quatro etapas, com os seguintes critérios:

- O cumprimento de cada etapa deve estar associado a um produto (geralmente um documento);

- Seu cumprimento deve ser de fácil verificação; e

- O cumprimento das quatro etapas deve implicar, obrigatoriamente, o cumprimento da meta revista.

Desse modo, foi possível incluir mesmo as atividades com produto impreciso, além de apreender avanços em etapas intermediárias, mesmo que a meta não tivesse sido nem parcialmente cumprida. Em cada rodada de monitoria, aos técnicos era solicitado atualizar o andamento das etapas, colocando "S" (de "Sim") para as etapas cumpridas, e "N" (de "Não") para as etapas ainda não cumpridas. Algumas etapas foram expressas em quantidades numéricas. Nesses casos, aos técnicos era solicitado atualizar a quantidade executada em cada etapa.

As consultas para atualização das etapas foram realizadas periodicamente, em planilhas enviadas via correio eletrônico. Quando uma etapa não estava concluída dentro do prazo estipulado, aos responsáveis era solicitada justificativa para o atraso.

A participação dos técnicos responsáveis por cada atividade no processo de enquadramento das etapas conferiu ao sistema coerência com as iniciativas adotadas pelo setor para atingir a meta revisada. As consultas pediam poucas informações, tendo como base etapas já plenamente conhecidas pelos executores (pois participaram de sua elaboração).

Com base na divisão das atividades em etapas, foi possível estabelecer, para cada uma delas, um indicador de execução expresso em porcentagem, onde cada etapa corresponde a $25 \%$ do andamento da atividade. Nos casos de etapas expressas em quantidades, andamentos parciais representam uma fração dos 25\% da etapa. Desse modo, uma atividade pode chegar a mais de $25 \%$ de execução, mesmo sem nenhuma etapa totalmente cumprida. A Tabela 1 mostra a atividade "Concessão Florestal em Florestas Nacionais". 


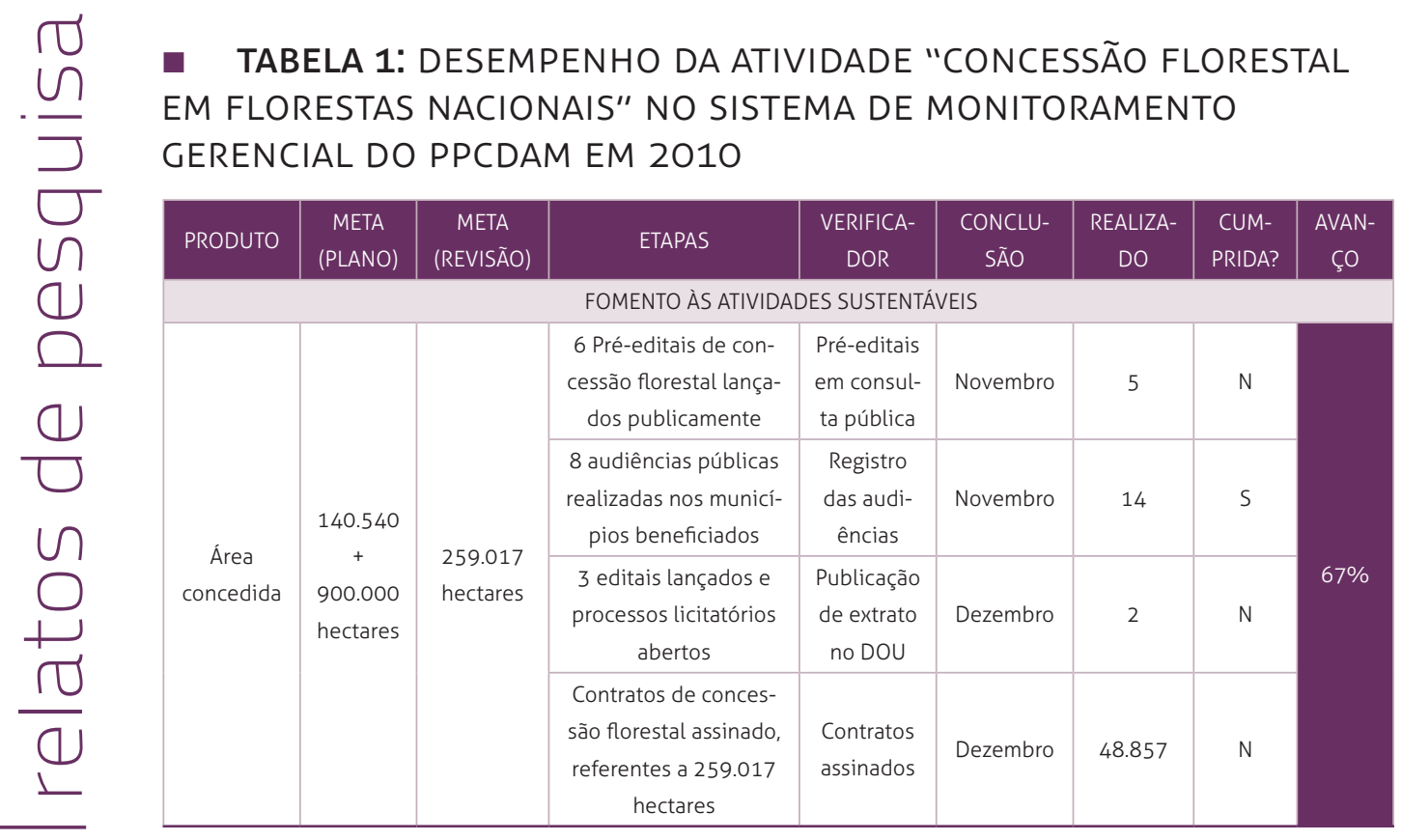

No caso acima, apenas uma das etapas foi cumprida, correspondendo a $25 \%$ do avanço da atividade. No entanto, ao considerar os cumprimentos parciais das demais etapas, o avanço da atividade ficou acima de $50 \%$.

É relevante observar que em diversos casos o monitoramento considerou avanços intermediários que não necessariamente representam o cumprimento da meta da atividade, como pode ser observado no exemplo acima. O percentual de avanço refere-se a todo o processo planejado no âmbito daquela ação, e por isso não deve ser entendido como percentual de cumprimento das metas.

O sistema por etapas vigorou somente para o ano de 2010. Ele não foi continuado em 2011 porque exige um grande esforço de preparação, incluindo reuniões presenciais com os responsáveis por cada ação. A possibilidade de realização de tal esforço em 2011 foi severamente prejudicado pelo período de transição de governo e pela elaboração do Plano Plurianual, que exigiu grande dedicação das equipes técnicas.

O sistema por etapas foi capaz de obter informações sobre a execução das atividades com razoável nível de detalhamento, em prazo reduzido.

No entanto, o sistema não apoiou a tomada de decisões, pois o volume de informações geradas era muito grande para que fossem consideradas com qualidade nas reuniões da Comissão Executiva. Avalia-se que seria necessária uma maior priorização, com seleção de menos atividades, ou um esforço prévio de tratamento das informações mais urgentes por parte do 
DPCD antes de apresentá-las à Comissão. Ademais, a fase de elaboração das etapas, com reuniões com todos os responsáveis e que deveria ocorrer todos os anos, revelou-se extremamente trabalhosa e demorada.

Apesar dessas limitações, avalia-se que o sistema representou um avanço no monitoramento das atividades do PPCDAm, e deverá ser continuada em sua terceira fase, com alguns ajustes.

\subsection{Monitoramento das ações de combate ao desmatamento por dados de satélite}

O Brasil é referência em monitoramento por satélite. Atualmente, diversos sistemas oriundos de dados de diferentes satélites, com características variadas, vêm sendo utilizados para subsidiar e monitorar ações de governo. O objetivo desta seção é expor como o Governo Federal vem utilizando os dados satelitais para o suporte e a avaliação crítica de políticas públicas.

\section{PROGRAMA DE MONITORAMENTO DA FLORESTA AMAZÔNICA BRASILEIRA POR SATÉLITE (PRODES)}

O Projeto PRODES quantifica a área desmatada na Amazônia usando classificação digital de imagens de satélite de média resolução (30 metros). As estimativas do
PRODES são consideradas como referência oficial para o Governo Federal. Este tópico demonstrará a utilização dos dados do PRODES pelo Governo Federal em duas esferas. Na primeira delas, as taxas anuais de desmatamento na Amazônia são usadas para o estabelecimento de uma meta nacional de redução do desmatamento. Na segunda, a flutuação dos incrementos anuais de desmatamento por município é utilizada para a construção de uma lista de municípios prioritários para as ações de prevenção e combate ao desmatamento.

\section{METAS DE REDUÇÃO DO DESMATAMENTO ESTABELECIDAS PELA POLÍTICA NACIONAL SOBRE MUDANÇAS NO CLIMA}

Do início do PPCDAm, em 2004, até a atualidade, a taxa anual de desmatamento na Amazônia vem sendo reduzida de forma acentuada. No entanto, temos ainda um grande desafio, considerando a meta fixada pela Política Nacional sobre Mudanças no Clima, formalizada pelo Decreto no 7390/2010, que prevê a redução de 80\% até 2020 da média das taxas anuais de desmatamento observadas entre 1996 e 2005, para redução das emissões de gases de efeito estufa por corte raso na Floresta Amazônica. Na figura 1, a linha tracejada azul representa a média do período de referência (1996-2005), a linha pontilhada preta é a meta de redução para 2020 e a verde é a redução alcançada em 2012. A linha pontilhada vermelha, por sua vez, demonstra a distância do número atual 
para a meta de 2020. Ou seja, restam $3,7 \%$ em relação ao período de referência e $15,7 \%$ em relação à taxa anual de 2012 para o alcance da meta. Considerando a taxa anual preliminar obtida para 2012, até agora alcançamos 76,3\% de redução em relação à média do perí- odo de referência. Se numericamente a maior parte do desafio já foi vencida, em termos práticos o maior esforço ainda está por vir, tendo em vista que a continuação da redução do desmatamento exigirá do governo novas estratégias de prevenção e controle.

- Figura 1: META do GOVERNo fEDERAL PARA REDUÇÃo das EMISSÕES DE GASES DE EFEITO ESTUFA POR CORTE RASO NA FLORESTA AMAZÔNICA ESTABELECIDAS PELA POLÍTICA NACIONAL SOBRE MUDANÇAS NO CLIMA (DECRETO NO7390/2010).

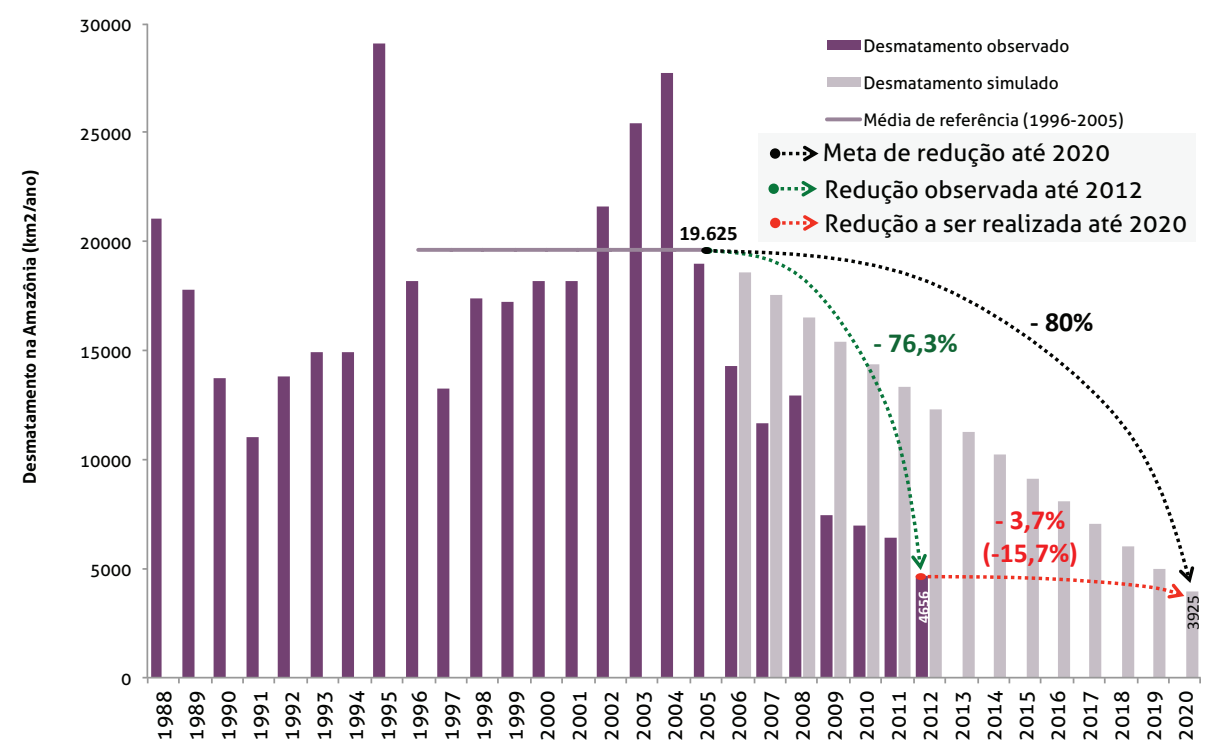

A linha tracejada azul representa a média do período de referência (1996-2005), a linha pontilhada preta é a meta de redução para 2020 e a verde é a redução alcançada em 2012. A linha pontilhada vermelha, por sua vez, demonstra a distância do número atual para a meta de 2020. 
POLÍTICA DE MUNICÍPIOS

PRIORITÁRIOS PARA AÇÕES DE

PREVENÇÃO E COMBATE AO

\section{DESMATAMENTO NA AMAZÔNIA}

$O$ artigo $2^{\circ}$ do Decreto $n^{0}$ 6.321/07 dispõe que o Ministério do Meio Ambiente (MMA) editará anualmente portaria com lista de municípios situados no Bioma Amazônia a serem considerados prioritários para ações de prevenção e controle do desmatamento. Esse decreto foi elaborado e negociado no âmbito do Plano de Ação para a Prevenção e o Controle do Desmatamento na Amazônia Legal (PPCDAm). Nesses municípios, fica impedida a emissão de novas autorizações de desmatamento acima de cinco módulos fiscais por ano, exceto se o imóvel possuir a certificação de georreferenciamento expedida pelo Instituto Nacional de Colonização e Reforma Agrária (INCRA), e ficam sujeitos à obrigatoriedade do recadastramento fundiário, de acordo com os normativos do INCRA.

Além disso, a priorização significa que nesses locais serão intensificadas as operações de fiscalização ambiental, como a Operação Arco de Fogo da Polícia Federal, e as políticas de fomento orientadas a apoiá-los na transição para um modelo de desenvolvimento local que valorize a floresta em pé, como é o caso da Operação Arco Verde.
Atualmente, 46 municípios fazem parte da lista dos prioritários e 6 municípios compõem a lista daqueles com desmatamento monitorado e sob controle. A seguir, para exemplificar o funcionamento da política, são apresentados dois exemplos de inclusão e exclusão em 2012.

Para que os municípios considerados como prioritários passassem a integrar a lista de municípios com desmatamento monitorado e sob controle em 2012, conforme estabelece a Portaria MMA no $186 / 2012$, eles devem atender aos seguintes critérios:

I - Possuir 80\% (oitenta por cento) de seu território, excetuadas as unidades de conservação de domínio público e terras indígenas homologadas, com imóveis rurais devidamente monitorados por meio do Cadastro Ambiental Rural (CAR);

II - O desmatamento ocorrido no ano de 2011 ter sido igual ou menor que $40 \mathrm{Km} 2$; e

III - A média do desmatamento nos anos de 2010 e 2011 ter sido igual ou inferior a $60 \%$ em relação à média dos anos de 2007, 2008 e 2009.

O município de Dom Eliseu (PA) alcançou $87,4 \%$ de imóveis rurais devidamente monitorados por meio do CAR; obteve 
25,8 Km2 de área desmatada em 2011; e a média dos anos 2010 e 2011 foi de $31,7 \mathrm{Km} 2$ (58,7\% em relação à média de $53,9 \mathrm{~km} 2$, referente ao período de 2007 a 2009). Portanto, em 2012 Dom Eliseu deixou a lista dos municípios prioritários.

De acordo com o artigo $2^{\circ}$ do Decreto no 6321 e os complementos e atualizações dadas pelas Portaria No 322/2012, para que um município adentre a lista dos prioritários ele deve se enquadrar nos seguintes critérios:

I - Área total de floresta desmatada;

II - Área total de floresta desmatada nos últimos três anos;

III - Aumento da taxa de desmatamento em pelo menos dois, dos últimos três períodos;

IV - Aumento do desmatamento de 2011 em relação ao desmatamento de 2010 e desmatamento em 2011 igual ou superior a $80 \mathrm{~km} 2$.

Aplicando-se os critérios da Portaria no 322/2012, Anapu (PA) e Senador José Porfírio (PA) foram acrescidos à lista dos municípios prioritários em 2012. Abaixo faz-se um detalhamento sobre o município de Anapu para exemplificação.

A área total desmatada em Anapu é de $2.239 \mathrm{Km} 2$, o que equivale a $18,8 \%$ de sua cobertura florestal. Nos últimos três anos, o desmatamento no município foi de 330,6 Km2. Neste período, Anapu teve dois aumentos nas taxas de desmatamen- to (2009-10 e 2010-11): o desmatamento em 2011 (226,8 km2) foi superior ao de $2010(77,3 \mathrm{Km} 2)$ e superior ao limiar estabelecido pelo critério IV de $80 \mathrm{Km} 2$.

\subsection{Sistema de Detecção de}

\section{Desmatamento em Tempo Real (DETER)}

O sistema DETER é um levantamento rápido feito pelo Instituto Nacional de Pesquisas Espaciais (INPE) com dados do sensor MODIS do satélite Terra/Aqua e do Sensor WFI do satélite CBERS. Foi desenvolvido como um sistema de alerta para suporte à fiscalização e ao controle do desmatamento. Captura apenas parte dos desmatamentos ocorridos, devido à menor resolução das imagens utilizadas e às restrições de cobertura de nuvens. Por esta razão, deve ser usado apenas como indicador de tendências do desmatamento.

Atualmente o Instituto Brasileiro de Meio Ambiente e Recursos Naturais Renováveis (IBAMA), que é responsável pela fiscalização ambiental no Brasil, recebe esses dados quase diariamente, podendo dessa forma subsidiar as operações de combate ao desmatamento. Esta estratégia foi responsável pela redução dos grandes polígonos de desmatamento na Amazônia. É resultado de uma forte ação de governo, advinda da integração do INPE, que gera o dado, com o IBAMA, que é um órgão executivo que opera a fiscalização. Essa integração teve grande impacto na queda da taxa de desmatamento. 
3.3 Programa de

Monitoramento do

Desmatamento nos Biomas Brasileiros por Satélite (PMDBBS)

O governo brasileiro lançou em 2007 os resultados do Projeto de Mapeamento da Cobertura Vegetal dos Biomas Brasileiros, um dos componentes do Projeto de Conservação e Utilização Sustentável da Diversidade (PROBIO), com o intuito de preencher momentaneamente a falta de estimativas de desmatamento fora da Amazônia7. Os resultados do PROBIO colocaram o Cerrado em evidência ao demostrar que até o ano de 2002 , 43,22\% do bioma apresentava vegetação antropizada. Dando continuidade à estratégia de monitoramento da cobertura vegetal dos biomas não amazônicos, foi criado o Projeto de Monitoramento dos Biomas Brasileiros por Satélite (PMDBBS) ${ }^{8}$. O principal objetivo do PMDBBS foi estender o monitoramento do desmatamento por satélite para as regiões brasileiras fora do bioma Amazônia (Cerrado, Caatinga, Mata Atlântica, Pampa e Pantanal), fornecendo subsídio às ações de fiscalização e planejamento da conservação.
Os primeiros anos de monitoramento demonstraram que o bioma Cerrado é aquele que vem perdendo sua cobertura vegetal nativa de forma mais acelerada. Entre 2002 e 2008, o incremento anual médio de desmatamento no Cerrado foi de $14.179 \mathrm{Km} 2 /$ ano. Em 2009, 7.637 Km2 de vegetação nativa foram suprimidos e em 2010 mais $6.469 \mathrm{Km} 2$ foram desmatados $^{9}$.

Como forma de contribuição à meta do governo em reduzir o desmatamento, o PPCerrado focou suas ações até 2012 nas regiões-chave nas quais ainda são encontradas grandes áreas de vegetação remanescente e que estão sofrendo intensa pressão pelos vetores de desmatamento. Assim, o Plano tem como prioridade de atuação as áreas consideradas de extrema importância para reduzir o desmatamento.

O artigo $2^{\circ}$ do Decreto $s / n^{\circ}$ de 15 de setembro de 2010, que institui o PPCerrado, versa que -MMA identificará periodicamente os municípios situados no Bioma Cerrado a serem considerados prioritários para ações de prevenção e controle do desmatamento.

7 SANO, E. E. et at. Mapeamento semidetalhado do uso da terra do Bioma Cerrado. Pesquisa Agropecuária Brasileira, v. 43, n. 1, 2008.

SANO, E. E. et al. Land cover mapping of the tropical savanna region in Brazil. Environmental Monitoring and Assessment, v. $166,2009$.

8 Brasil. Ministério do Meio Ambiente. Relatório técnico de monitoramento do desmatamento no bioma Cerrado, 20022008: dados revisados. MMA, Brasília. 2009. <http://www.mma.gov.br/estruturas/sbf_chm_rbbio/_arquivos/relatorio_tecnico_monitoramento_desmate_bioma_cerrado_csr_ibama_2002_2008_rev_72.pdf> (Acessado em 13 de julho de 2012).

9 Brasil. Ministério do Meio Ambiente. Plano de Ação para Prevenção e Controle do Desmatamento e das Queimadas no Cerrado - PPCerrado. Brasília, 2011. <http://www.mma.gov.br/estruturas/201/_arquivos/ppcerrado_201.pdf> (Acessado em 13 de junho de 2013).

Revista Brasileira de Monitoramento e Avaliação | Número 5 | Janeiro-Junho de 2013 
Para a identificação dos municípios, o decreto do Plano estabelece que devem ser priorizadas as áreas consideradas de maior importância para a biodiversidade e para os recursos hídricos do bioma, as unidades de conservação, as terras indígenas e quilombolas e os municípios com índices elevados de desmatamento.

Com o intuito de atender ao proposto no decreto, a Portaria MMNono 97/2012 estabeleceu os seguintes critérios para identificação de municípios prioritários no Cerrado:

I. Desmatamento corrente (2010) maior que a média dos desmatamentos no bioma nos períodos de 2008 a $2010(5,08 \mathrm{~km} 2)$;

II. Desmatamento corrente (2010) superior a $25 \mathrm{Km} 2$; e

III. Áreas de vegetação nativa remanescente superior a $20 \%$ da área do município ou presença de áreas protegidas (Terras Indígenas, Terras Quilombolas e Unidades de Conservação).

Em termos quantitativos, os municípios selecionados pela aplicação dos critérios abrangem $44 \%$ do desmatamento e $22 \%$ dos remanescentes do bioma no período 2009/2010. A seleção de apenas 4\% das unidades administrativas (municípios) que compõem o bioma Cerrado cobre $44 \%$ do desmatamento corrente. Ou seja, dos 1.388 municípios presentes no bioma Cerrado, apenas 53 cobriram 44\% do desmatamento em 2010.

A intervenção pontual do Governo Federal nos municípios selecionados pode otimi- zar as ações de prevenção e controle do desmatamento no Cerrado, contribuindo, dessa forma, para a redução do desmatamento e alcance do compromisso voluntário assumido no âmbito da Política Nacional de Mudanças Climáticas, que prevê até 2020 a redução de $40 \%$ das emissões oriundas de desmatamento no Cerrado em relação à média verificada entre os anos de 1999 a 2020.

\subsection{Outros sistemas de monitoramento por satélite operantes no Brasil}

Outro sistema de monitoramento por satélite que vem sendo utilizado para a identificação de áreas em processo de desmatamento é o Indicativo de Desmatamento por Imagens de Radar (INDICAR). O INDICAR é fruto de uma parceria entre o Centro de Sensoriamento Remoto do IBAMA e a Agência Espacial Japonesa (JAICA). A vantagem do INDICAR sobre os demais sistemas advém da utilização de imagens de radar (ALOS). Como os radares são sensores ativos que operam na faixa das micro-ondas, a cobertura de nuvens não interfere no imageamento. Embora a maior parte do desmatamento ocorra durante a época seca, ultimamente o desmate no período chuvoso tem sido praticado na tentativa de evitar ou postergar a detecção por satélite. Portanto, o sistema apresenta elevada complementariedade aos demais, principalmente quando a Amazônia está coberta por nuvens, sendo uma excelente ferramenta para as ações de fiscalização durante o período chuvoso. 
Além de identificar que a floresta de uma determinada área foi removida, é importante saber qual uso do solo foi implementado após o desmatamento. A comunidade científica de estudiosos sobre o tema passou as últimas décadas olhando para o desmatamento da Amazônia como uma grande mancha em que não era possível saber o que tinha acontecido após a remoção da floresta. Recentemente, no entanto, foi criado (TerraClas), que qualificou o uso do solo das áreas desmatadas e possibilitou um novo olhar para o desmatamento da Amazônia. Esse produto é realizado em parceria pelo INPE e pela Empresa Brasileira de Pesquisa Agropecuária (EMBRAPA). Os resultados foram surpreendentes. Foi possível verificar que $21 \%$ da área desmatada da Amazônia regenerou e encontra-se como vegetação secundária. Por outro lado, mais de $60 \%$ das áreas desmatadas foram destinadas à pecuária e menos de $5 \%$ apresentam agricultura. A compreensão da dinâmica do uso do solo é extremamente importante no ordenamento e planejamento de ações de desenvolvimento sustentável e fomento às atividades produtivas. Estes dados vêm sendo utilizados para subsidiar ações desta natureza.

Os incêndios florestais e queimadas também são monitorados por diversos satélites. Os sensores utilizam o comprimento de onda infravermelho termal para apontar pixels com temperaturas acima do normal. Estes pixels são posteriormente convertidos em pontos denominados focos de calor e disponibilizados pelo INPE. Estes dados são gerados em alta resolução tempore e as informações são atualizadas várias vezes ao dia. O Centro Nacional de Prevenção e Combate aos Incêndios Floresta - (Prevfogo) utiliza constantemente estes dados para planejar atividades, como priorização de áreas, alocação de equipes de brigadistas, distribuição de recursos, execução de atividades educativas, monitoramento, controle de queimadas, prevenção e combate aos incêndios florestais em todo o território nacional.

\section{Conclusões e recomendações}

Esse relato apresentou um sistema de monitoramento gerencial implantado com relativo sucesso para uma política pública sob responsabilidade de diferentes setores do Governo Federal. O principal desafio enfrentado foi a escassez de incentivos a oferecer em troca das informações. Para superá-lo, buscou-se assumir uma posição de neutralidade no trato das informações, simplificando-as de modo a facilitar a atualização por parte dos executores. O texto demostrou também que as aplicações de Sistemas de Informações Geográficas (SIG) e análises espaciais apresentam elevado potencial no planejamento, acompanhamento e avaliação de políticas públicas. O uso deste arcabouço de ferramentas, no entanto, ainda é incipiente nos órgãos de governo, sendo mais difundidos na área ambiental. 